\title{
Assessing coronary disease in patients with severe aortic stenosis: the need for a 'valid' gold standard for validation studies?
}

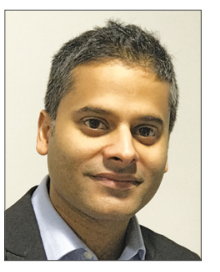

\author{
Sayan Sen ${ }^{1,2}$, MRCP, PhD; Yousif Ahmad ${ }^{1,2}$, MRCP; Justin Davies ${ }^{1,2 *}$, MRCP, PhD
}

1. International Centre for Circulatory Health, National Heart and Lung Institute, Imperial College London, London, United Kingdom; 2. Imperial College Healthcare NHS Trust, Hammersmith Hospital, London, United Kingdom

A significant proportion of patients with severe aortic stenosis have concomitant coronary disease $\mathrm{e}^{1,2}$. The decision to intervene on such disease has traditionally been guided by angiographic appearance. Intracoronary physiology has been demonstrated to be more accurate than angiography when determining which stenoses need to be treated ${ }^{3}$. However, patients with significant valve disease have been excluded from all validation ${ }^{4,5}$ and randomised studies $^{6,7}$ involving these tools. Therefore, the role of such techniques in these patients is yet to be determined. In this issue of EuroIntervention, Scarsini et $\mathrm{al}^{8}$ compare diagnostic categorisation of the instantaneous wave-free ratio (iFR) to fractional flow reserve (FFR) in 66 patients (145 lesions) before and after transcatheter aortic valve implantation (TAVI).

\section{Article, see page 1512}

The procedures were performed by a group skilled in physiological research, in patients under local anaesthetic to minimise any haemodynamic perturbations. Physiological assessment was made as soon as possible post valve insertion. The mean iFR value pre TAVI across the population was identical to the mean
FFR value. iFR pre TAVI had a negative predictive value of $98.8 \%$. The mean iFR pre TAVI was identical to the iFR value post TAVI. There was a $15 \%$ categorisation change by iFR after TAVI.

Their study highlights three important aspects of the assessment of any physiological index in a new clinical context: 1) the need for a valid reference standard; 2) the importance of understanding stenosis distribution when interpreting results; and 3) the need for further studies in this field.

\section{The importance of a valid reference standard}

FFR is dependent on maximal hyperaemia. In patients with aortic stenosis this is significantly impaired due to a complex interplay between the stenotic valve, elevated left ventricular end-diastolic pressure, left ventricular hypertrophy and the associated negative remodelling of the coronary microcirculation ${ }^{9,10}$. These factors result in an impaired response to hyperaemic agents such as adenosine $^{11}$. Patients with aortic stenosis have therefore been excluded from all the pivotal clinical studies of FFR. 
The identical iFR and FFR values in Scarsini's study demonstrate the inability of adenosine to increment flow above that of baseline in these patients. The inability to achieve maximal hyperaemia invalidates the physical principles upon which FFR depends and therefore calls into question the validity of using this index as a reference standard in patients with aortic stenosis, and certainly the use of the 0.80 cut-point used in this study. The negative and positive predictive values derived in this study should be interpreted with this in mind. Indeed, studies using coronary flow velocity as well as pressure have highlighted the sensitivity of hyperaemic indices to aortic stenosis ${ }^{12}$. Interestingly, such studies suggest that hyperaemic parameters are more susceptible to change post TAVI than resting parameters. This is consistent with Scarsini's results, demonstrating identical average iFR values pre and post TAVI.

\section{The importance of stenosis distribution}

The mean iFR pre TAVI was identical to the mean iFR post TAVI (0.89). However, in $15 \%$ of patients iFR categorisation of coronary stenosis severity changed post TAVI. The direction of change was unpredictable and higher than the categorisation change with FFR. To conclude that iFR is more sensitive than FFR to aortic stenosis based on this fails to appreciate the role of population distribution and the limitations of using a continuous variable dichotomously. The apparent greater categorisation change is simply a result of the distribution of iFR values when compared to FFR values. The majority of patients in this study had iFR values that grouped around the iFR cut-point, either just above or just below. Any biological variation will therefore lead to treatment reclassification of a large proportion of patients when the inherent variability of iFR causes its value to drop below or climb just above the treatment threshold post TAVI. In contrast, the majority of patients had
FFR values (mean pre-TAVI FFR 0.88) that were significantly further away from the FFR cut-point (due to inadequate hyperaemia); the number of patients with FFR values around the 0.80 threshold was significantly less than the number of patients with iFR values around 0.89 . Therefore, any numerical variation in FFR resulted in fewer patients having their stenosis classification changed (Figure 1). The categorisation change or lack of change is therefore an artefact of using a continuous variable such as FFR or iFR dichotomously, the inability to achieve a true FFR due to a lack of hyperaemia and stenosis distribution. In such a scenario, the index with a mean value (majority of patients) far away from the cutpoint can appear to have less categorisation variability despite the same numerical variability. This categorisation variability around the treatment threshold has been defined in FFR. When measured 10 minutes apart in the same patient, FFR itself has a categorisation change in $15 \%$, increasing to $50 \%$ when FFR values are close to the treatment threshold ${ }^{13}$.

Whether the categorisation change with iFR was due to the aortic valve or due to the inherent variability of the biological index cannot be answered by Scarsini's study. To answer this question would require the iFR to be measured twice pre TAVI and then measured twice post TAVI and the inherent variability compared with the iFR change pre compared to post TAVI in each patient.

But does classification change have clinical implications in the TAVI patient? On balance, it appears that using iFR may mean a few additional stents are inserted, whilst using FFR risks inappropriate deferral of haemodynamically significant stenoses. Overall, it is more likely that, if clinicians use coronary physiology in these patients, they will use it for clear exclusion of very significant disease that may increase the risk of the TAVI procedure itself. Borderline lesions are unlikely to require intervention
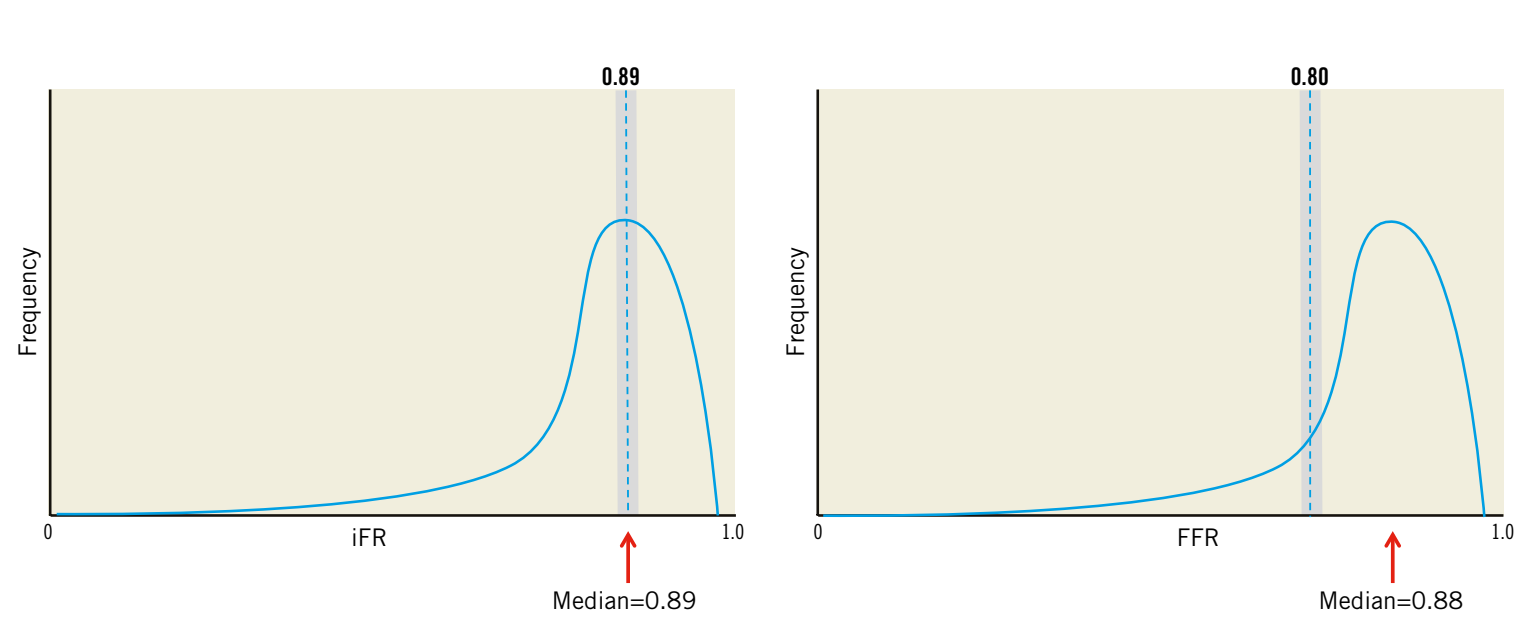

Figure 1. The importance of stenosis distribution on treatment categorisation. The majority of iFR values (left panel) centred around the iFR cut-point (0.89). As a result, any inherent variability of iFR exposes a large proportion of patients (grey area under the curve) to dropping either just below or just above the treatment threshold. However, a minority of FFR values centred around the FFR cut-point (0.80) due to an inability to achieve hyperaemia. As a result, fewer patients (grey area under the curve) were reclassified despite the same inherent variability of FFR. Treatment reclassification is therefore dependent on stenosis distribution and the treatment threshold, which is yet to be defined for FFR in this context. 
prior to valve insertion, and are probably most appropriately managed with medical therapy, even in the medium term post TAVI.

\section{The need to elucidate the clinical role of coronary physiology in patients with severe aortic stenosis}

Scarsini and colleagues should be congratulated for attempting to define coronary stenosis severity physiologically in the context of aortic stenosis. Their study contributes to a growing number of studies that are beginning to unpick the complex physiology in these patients ${ }^{14}$. The ability to elucidate coronary stenosis severity independent of aortic valve severity may become increasingly clinically relevant as the use of TAVI increases and it is applied to a larger and lower-risk patient population ${ }^{15,16}$. This study poses the dilemma of how to validate an invasive index of stenosis severity when all invasive indices have thus far not studied such patients. Their findings question the role of FFR as the reference standard in this context as they clearly demonstrate the inability of adenosine to increment flow.

Investigators in this field must now answer several further questions before we can appreciate a role for coronary physiology in these patients: at which point of aortic stenosis severity does hyperaemic flow become impaired? How does this affect the cutpoint for FFR, and is this predictable? How do we validate iFR or any other index in these patients? Do we actually need a physiological index in these patients or should we just treat the valve and leave all, except for severe proximal disease, to be assessed and treated after the valve has been replaced? If the latter, how long should we wait post TAVI to assess coronary stenosis severity and which index should we use?

Whilst a plethora of questions remain, this study clearly suggests that, due to a lack of a valid reference standard, the role of iFR in these patients will have to be determined by randomised clinical trials comparing clinical endpoints between iFR-guided treatment and standard angiographically guided treatment. Ultimately, we will have to use the patient as the gold standard.

\section{Conflict of interest statement}

S. Sen has received grants/honoraria from participation in educational programmes supported by St. Jude, Pfizer, AstraZeneca and Philips Volcano. J. Davies has received grants/personal fees from Volcano Corporation, Medtronic, ReCor Medical and AstraZeneca. Y. Ahmad has no conflicts of interest to declare.

\section{References}

1. Stewart BF, Siscovick D, Lind BK, Gardin JM, Gottdiener JS, Smith VE, Kitzman DW, Otto CM. Clinical factors associated with calcific aortic valve disease. Cardiovascular Health Study. J Am Coll Cardiol. 1997;29:630-4.

2. Iung B. Interface between valve disease and ischaemic heart disease. Heart. 2000;84:347-52.

3. Tonino PA, De Bruyne B, Pijls NH, Siebert U, Ikeno F, van' t Veer M, Klauss V, Manoharan G, Engstrøm T, Oldroyd KG, Ver
Lee PN, MacCarthy PA, Fearon WF; FAME Study Investigators. Fractional flow reserve versus angiography for guiding percutaneous coronary intervention. $N$ Engl J Med. 2009;360:213-24.

4. Sen S, Escaned J, Malik IS, Mikhail GW, Foale RA, Mila R, Tarkin J, Petraco R, Broyd C, Jabbour R, Sethi A, Baker CS, Bellamy M, Al-Bustami M, Hackett D, Khan M, Lefroy D, Parker KH, Hughes AD, Francis DP, Di Mario C, Mayet J, Davies JE. Development and validation of a new adenosine-independent index of stenosis severity from coronary wave-intensity analysis: results of the ADVISE (ADenosine Vasodilator Independent Stenosis Evaluation) study. J Am Coll Cardiol. 2012; 59:1392-402.

5. De Bruyne B, Baudhuin T, Melin JA, Pijls NH, Sys SU, Bol A, Paulus WJ, Heyndrickx GR, Wijns W. Coronary flow reserve calculated from pressure measurements in humans. Validation with positron emission tomography. Circulation. 1994;89:1013-22.

6. Davies JE, Sen S, Dehbi HM, Al-Lamee R, Petraco R, Nijjer SS, Bhindi R, Lehman SJ, Walters D, Sapontis J, Janssens L, Vrints CJ, Khashaba A, Laine M, Van Belle E, Krackhardt F, Bojara W, Going O, Härle T, Indolfi C, Niccoli G, Ribichini F, Tanaka N, Yokoi H, Takashima H, Kikuta Y, Erglis A, Vinhas H, Canas Silva P, Baptista SB, Alghamdi A, Hellig F, Koo BK, Nam CW, Shin ES, Doh JH, Brugaletta S, Alegria-Barrero E, Meuwissen M, Piek JJ, van Royen N, Sezer M, Di Mario C, Gerber RT, Malik IS, Sharp ASP, Talwar S, Tang K, Samady H, Altman J, Seto AH, Singh J, Jeremias A, Matsuo H, Kharbanda RK, Patel MR, Serruys P, Escaned J. Use of the Instantaneous Wave-free Ratio or Fractional Flow Reserve in PCI. $N$ Engl J Med. 2017; 376:1824-34.

7. De Bruyne B, Pijls NH, Kalesan B, Barbato E, Tonino PA, Piroth Z, Jagic N, Möbius-Winkler S, Rioufol G, Witt N, Kala P, MacCarthy $P$, Engström $T$, Oldroyd $K G$, Mavromatis $K$, Manoharan G, Verlee P, Frobert O, Curzen N, Johnson JB, Jüni P, Fearon WF; FAME 2 Trial Investigators. Fractional flow reserveguided PCI versus medical therapy in stable coronary disease. N Engl J Med. 2012;367:991-1001.

8. Scarsini R, Pesarini G, Zivelonghi C, Piccoli A, Ferrero V, Lunardi M, Gottin L, Zanetti C, Faggian G, Ribichini F. Physiologic evaluation of coronary lesions using instantaneous wave-free ratio (iFR) in patients with severe aortic stenosis undergoing transcatheter aortic valve implantation. EuroIntervention. 2018;13: 1512-19.

9. Danson E, Hansen P, Sen S, Davies J, Meredith I, Bhindi R. Assessment, treatment, and prognostic implications of CAD in patients undergoing TAVI. Nat Rev Cardiol. 2016;13:276-85.

10. Davies JE, Sen S, Broyd C, Hadjiloizou N, Baksi J, Francis DP, Foale RA, Parker KH, Hughes AD, Chukwuemeka A, Casula R, Malik IS, Mikhail GW, Mayet J. Arterial pulse wave dynamics after percutaneous aortic valve replacement: fall in coronary diastolic suction with increasing heart rate as a basis for angina symptoms in aortic stenosis. Circulation. 2011;124:1565-72.

11. Choudhury L, Rosen SD, Patel D, Nihoyannopoulos P, Camici PG. Coronary vasodilator reserve in primary and secondary 
left ventricular hypertrophy. A study with positron emission tomography. Eur Heart J. 1997;18:108-16.

12. Wiegerinck EM, van de Hoef TP, Rolandi MC, Yong Z, van Kesteren F, Koch KT, Vis MM, de Mol BA, Piek JJ, Baan J Jr. Impact of Aortic Valve Stenosis on Coronary Hemodynamics and the Instantaneous Effect of Transcatheter Aortic Valve Implantation. Circ Cardiovasc Interv. 2015;8:e02443.

13. Petraco R, Sen S, Nijjer S, Echavarria-Pinto M, Escaned J, Francis DP, Davies JE. Fractional flow reserve-guided revascularization: practical implications of a diagnostic gray zone and measurement variability on clinical decisions. JACC Cardiovasc Interv. 2013;6:222-5.

14. Sen S, Davies JE. Demystifying Complex Coronary Hemodynamics in Patients Undergoing Transcatheter Aortic Valve Replacement: Sowing the Seeds for Coronary Physiological Assessment in the Future? Circ Cardiovasc Interv. 2015;8: e002909.
15. Leon MB, Smith CR, Mack MJ, Makkar RR, Svensson LG, Kodali SK, Thourani VH, Tuzcu EM, Miller DC, Herrmann HC, Doshi D, Cohen DJ, Pichard AD, Kapadia S, Dewey T, Babaliaros V, Szeto WY, Williams MR, Kereiakes D, Zajarias A, Greason KL, Whisenant BK, Hodson RW, Moses JW, Trento A, Brown DL, Fearon WF, Pibarot P, Hahn RT, Jaber WA, Anderson WN, Alu MC, Webb JG; PARTNER 2 Investigators. Transcatheter or Surgical Aortic-Valve Replacement in Intermediate-Risk Patients. $N$ Engl J Med. 2016;374:1609-20.

16. Reardon MJ, Van Mieghem NM, Popma JJ, Kleiman NS, Søndergaard L, Mumtaz M, Adams DH, Deeb GM, Maini B, Gada H, Chetcuti S, Gleason T, Heiser J, Lange R, Merhi W, Oh JK, Olsen PS, Piazza N, Williams M, Windecker S, Yakubov SJ, Grube E, Makkar R, Lee JS, Conte J, Vang E, Nguyen H, Chang Y, Mugglin AS, Serruys PW, Kappetein AP; SURTAVI Investigators. Surgical or Transcatheter Aortic-Valve Replacement in Intermediate-Risk Patients. N Engl J Med. 2017;376:1321-31. 